\title{
Epidemiology and Management of Peritonitis at a Rural Hospital in Zambia
}

\author{
Sergiy Karachentsev \\ Roan Antelope General Hospital, Zambia
}

Correspondence to: Dr. Sergiy Karachentsev; email: sergek69@yahoo.co.uk.

\begin{abstract}
Background: Peritonitis is a common surgical emergency with varying etiologies encountered the world over. It is associated with significant morbidity and mortality despite intensive research and advances in management. Methods: Records of 119 patients operated on for peritonitis at a rural surgical hospital in Zambia over a 10-year period were retrospectively reviewed. Results: Common sources of peritonitis were perforated peptic ulcer, acute appendicitis, pelvic inflammatory disease, and perforated terminal ileum. Postoperative period became complicated in 42 patients (32.3\%). Fourteen patients (11.8\%) died postoperatively; the highest level of mortality was in patients with perforated peptic ulcer (26\%). Organ failure was found in 29 patients $(24.4 \%)$ and was associated with increased risk of death. Conclusions: Individual approach with identifying signs of organ failure is essential to determine
\end{abstract}

\section{Introduction}

Peritonitis continues to generate debate in the surgical community worldwide, as morbidity and mortality are still unacceptably high (1). This is especially true in a developing world setting with a huge burden of community-acquired urgent surgical conditions and limited access to modern diagnostic and therapeutic facilities (2). Despite its importance, the problem of peritonitis remains far from resolved and some areas of management have not been covered yet.

First, the spectrum of the disease in developing nations is different from that found in the western world and could vary from country to country (3). There is a paucity of research on complicated intra-abdominal infection in central and southern Africa. Second, studies originating from developing countries produce data predominantly from the tertiary referral hospitals of metropolitan areas $(4,5)$. As a result, the rural population, which dominates in the developing countries, becomes under-represented in research with only isolated articles published (6-8). Third, and connected to the above, the role of a rural the patient's prognosis and decide on the level of care. Patients without organ dysfunction can be successfully managed in a rural surgical hospital.

Keywords: Peritonitis, Epidemiology, Morbidity, Mortality, Rural hospital, Zambia

Ann Afr Surg. 2020;17(3):120-125

DOI: http://dx.doi.org/10.4314/aas.v17i3.7

Conflicts of Interest: None

Funding: None

(C) 2020 Author. This work is licensed under the Creative Commons Attribution 4.0 International License.

Submitted: 28 November 2019

Revised: 1 March 2020

Accepted: 30 March 2020

Online first: 29 May 2020 surgeon in the management of peritonitis still remains unclear, even after publication of the Lancet Commission recommendations 'Global Surgery 2030' (9).

This study, therefore, aimed to evaluate the etiology of peritonitis among the rural population of Zambia and to assess risk factors leading to lethal outcome. Findings could be of value for rural surgeons facing the dilemma of operating patients immediately, or referring them to the tertiary center for further management. The author believes that both epidemiological and risk-related components of the study will help in decision-making and show ways to reduce morbidity and mortality, the ultimate goal of this work.

\section{Materials and Methods}

All patients with peritonitis admitted to Roan Antelope General Hospital, Zambia, from 16 March 2009 to 24 September 2019 were retrospectively identified from patient records. This is a second level referral hospital having a capacity of 350 beds and operating as the main medical center in the area with the population of around 
200,000 people. Permission to conduct the study and to publish results was sought from the Hospital Ethical Committee.

Out of 128 patients, six patients who were referred to continue treatment elsewhere and three patients with suspected peritonitis who died before surgery were excluded from the study. Three patients who were operated in other institutions and transferred to our hospital were included in the research.

Demographic data, length of the history, physiological parameters, laboratory values, diagnostic investigations, and outcomes were compiled from medical records. Positive abdominal findings included abdominal pain, rigidity of abdominal wall muscles and positive rebound sign. A patient considered to have organ dysfunction presented with signs of altered mental status (agitation, somnolence, disorientation), systolic blood pressure $<100$ $\mathrm{mmHg}$, respiratory rate $>22 / \mathrm{min}$, urine output $<20 \mathrm{~mL} / \mathrm{h}$, and laboratory findings of creatinine $\geq 177 \mu \mathrm{mol} / \mathrm{L}$ and urea $\geq 16.7 \mathrm{mmol} / \mathrm{L}$. X-ray and ultrasonography of the abdomen were done to aid in diagnosis as per requirement. Free gas in peritoneal cavity found on $\mathrm{x}$-ray characteristically suggested perforated hollow viscus. Presence of distended bowel loops was an additional sign of secondary paralytic ileus. Positive findings on ultrasound abdomen included free intraperitoneal fluid, absence of bowel activity, and dilation of bowel. Intravenous (IV) fluid resuscitation, administration of broad-spectrum antibiotics and nasogastric decompression started early on admission. Outcome data included morbidity and mortality related to the surgery within one month of the procedure.

Data are presented in frequency tables and percentages as well as graphical representation. Outcome related to different etiologies are compared. Continuous variables are expressed as mean \pm standard deviation (SD) and median including ranges; categorical data are expressed as absolute figures and percentages. Statistical evaluation of data used Student's $t$ test, Fisher's exact test and oneway ANOVA test, where appropriate. A p-value of $<.05$ was considered significant.

\section{Results}

Out of 119 patients, 73 were men (61.4\%) and 46 were women $(38.6 \%)$. Age range was 8 to 72 years, with peak incidence in the 21-30-year age group. Table 1 shows age distribution by gender and source of peritonitis.

The main etiological factors of peritonitis and associated morbidity and mortality were perforated peptic ulcer (27 patients) and acute appendicitis (26 patients), next were pelvic inflammatory disease (22 patients), perforation of small bowel (16 patients), and abdominal trauma (9 patients) (Table 1). Mean age differed across the groups; the youngest cohort appeared to be of abdominal trauma while the oldest group was of perforated peptic ulcer. The difference in mean age between the groups was determined by one-way ANOVA test and found to be statistically significant $(F 5,113=5.95, p<.0005)$. Of nine patients with abdominal trauma, seven sustained blunt injury while two were operated for penetrated stab wounds. Injuries to the small bowel were found in six patients, to the stomach in two, colon in one, uterus in one, and the gallbladder in one. Two patients had combined traumas: stomach+small bowel and stomach + colon. Other sources of peritonitis were as follows: intestinal obstruction $(n=6)$, acute pancreatitis $(n=3)$, spleen abscess $(n=2)$, acute perforated cholecystitis $(n=1)$, strangulated inguinal hernia $(n=1)$, acute mesenteric ischemia with necrosis of ileum $(n=1)$, perforated carcinoma of sigmoid colon $(n=1)$, inguinal lymphadenitis and pararectal abscess with formation of pelvic abscesses $(n=2)$. In two patients, laparotomy revealed primary peritonitis due to widespread abdominal tuberculosis and advanced tumor of ovarium. Risk factors for lethal outcome were determined using Mannheim peritonitis index (MPI), which was calculated for each patient (Table 2).

Procedures were performed after patients' condition were preoperatively optimized, which started shortly after the primary survey in the Emergency Department. In cases of hemodynamic instability, patients were offered intensive IV resuscitation with repeated boluses of fluids and hourly control of urinary output.

All perforated peptic ulcers were located in the anterior wall of proximal duodenum or pre-pyloric area of the stomach (type III, according to modified Johnson classification). The common operation was primary closure $(n=15)$. In 11 patients, omental pedicle flap was employed to secure the suture line. In one patient, peptic ulcer was excisioned with Heineke-Mikulitz pyloroplasty. Patients with perforated appendicitis were operated using open procedure with lower midline laparotomy. Five appendectomies were also done as part of other procedures. Patients with generalized peritonitis caused by pelvic inflammatory disease (PID) were managed by eliminating the source of infection (oophorectomy, tubectomy) and copious washout with normal saline solution. Spontaneous perforations of small bowel were characteristically located within $90 \mathrm{~cm}$ of the terminal ileum. 
Table 1. Patient demographics and outcomes

\begin{tabular}{|c|c|c|c|c|c|c|c|}
\hline Characteristics & Total & $\begin{array}{l}\text { Perforated } \\
\text { peptic } \\
\text { ulcer }\end{array}$ & $\begin{array}{l}\text { Acute } \\
\text { appendiciti } \\
\mathbf{s}\end{array}$ & PID & $\begin{array}{l}\text { Spontaneou } \\
\text { s perforation } \\
\text { of small } \\
\text { bowel }\end{array}$ & $\begin{array}{l}\text { Abdominal } \\
\text { trauma }\end{array}$ & Others \\
\hline Number (M/F) & $119(73 / 46)$ & $27(24 / 3)$ & $26(20 / 6)$ & 22 & $16(12 / 4)$ & $9(7 / 2)$ & $19(11 / 8)$ \\
\hline $\begin{array}{l}\text { Age (years) } \\
\text { mean } \pm S D \\
\text { median (range) }\end{array}$ & $\begin{array}{l}32.5 \pm 15.0 \\
29.5(8-72)\end{array}$ & $\begin{array}{c}38.9 \pm 7.3 \\
32.5(22-72)\end{array}$ & $\begin{array}{c}34.4 \pm 17.1 \\
30.5(8-67)\end{array}$ & $\begin{array}{c}25.5 \pm 9.1 \\
22.0(15-39)\end{array}$ & $\begin{array}{c}28.1 \pm 13.6 \\
27.5(12-62)\end{array}$ & $\begin{array}{c}25.3 \pm 5.4 \\
25.0(21-36)\end{array}$ & $\begin{array}{c}34.9 \pm 11.2 \\
30.5(18-64)\end{array}$ \\
\hline $\begin{array}{l}\text { Duration of } \\
\text { symptoms, } \\
\text { mean } \pm S D \text { (days) } \\
\text { median (days) } \\
\text { (range) }\end{array}$ & $\begin{array}{c}4.5 \pm 2.8 \\
2.5 \\
(4 \mathrm{~h}-2 \\
\text { weeks })\end{array}$ & $\begin{array}{c}6.2 \pm 3.2 \\
3.5 \\
\text { (3 days-2 } \\
\text { weeks) }\end{array}$ & $\begin{array}{c}5.4 \pm 2.6 \\
3.5 \\
\text { (2-10 days) }\end{array}$ & $\begin{array}{c}2.0 \pm 0.7 \\
1.5 \\
\text { (1-3 days) }\end{array}$ & $\begin{array}{c}5.6 \pm 3.3 \\
1.2 \\
\text { (7 h-9 days) }\end{array}$ & $\begin{array}{c}1.4 \pm 0.8 \\
1.1 \\
(4 \mathrm{~h}-2 \text { days })\end{array}$ & $\begin{array}{c}4.0 \pm 2.2 \\
5.0 \\
(2-10 \text { days })\end{array}$ \\
\hline $\begin{array}{l}\text { Organ } \\
\text { dysfunction: } \\
\text { number/ \% }\end{array}$ & $29 / 24.4$ & $12 / 44$ & $3 / 12$ & $3 / 14$ & $4 / 25$ & $3 / 33$ & $4 / 21$ \\
\hline $\begin{array}{l}\text { Morbidity: } \\
\text { number/\% }\end{array}$ & $42 / 35.3$ & $12 / 44$ & $6 / 23$ & $5 / 23$ & $8 / 50$ & $5 / 56$ & $6 / 32$ \\
\hline $\begin{array}{l}\text { Mortality: } \\
\text { number/ \% }\end{array}$ & $14 / 11.8$ & $7 / 26$ & $1 / 4$ & 2/9.5 & $1 / 6$ & 0 & $3 / 16$ \\
\hline
\end{tabular}

Table 2. Risk factors of Mannheim peritonitis index and mortality

\begin{tabular}{|c|c|c|c|c|}
\hline Risk factors & $\begin{array}{l}\text { Survivor } \\
\text { s }\end{array}$ & $\begin{array}{l}\text { Expire } \\
\text { d }\end{array}$ & $\mathbf{R R}$ & $\begin{array}{l}\text { Fisher' } \\
\text { s } \\
p \\
\text { value }\end{array}$ \\
\hline \multicolumn{5}{|l|}{ Age (years) } \\
\hline $\begin{array}{l}>50 \\
<50\end{array}$ & $\begin{array}{l}13 \\
92\end{array}$ & $\begin{array}{l}3 \\
11\end{array}$ & 1.75 & .40 \\
\hline \multicolumn{5}{|l|}{ Gender } \\
\hline $\begin{array}{l}\text { Female } \\
\text { Male }\end{array}$ & $\begin{array}{l}40 \\
65\end{array}$ & $\begin{array}{l}6 \\
8\end{array}$ & 1.19 & .78 \\
\hline \multicolumn{5}{|l|}{ Organ failure } \\
\hline $\begin{array}{l}\text { Yes } \\
\text { No }\end{array}$ & $\begin{array}{l}17 \\
88\end{array}$ & $\begin{array}{l}12 \\
2\end{array}$ & $\begin{array}{l}18.6 \\
2\end{array}$ & $<.00001$ \\
\hline \multicolumn{5}{|l|}{ Malignancy } \\
\hline $\begin{array}{l}\text { Yes } \\
\text { No }\end{array}$ & $\begin{array}{l}1 \\
104\end{array}$ & $\begin{array}{l}1 \\
13\end{array}$ & 4.5 & .22 \\
\hline $\begin{array}{l}\text { Origin of } \\
\text { sepsis not } \\
\text { colonic }\end{array}$ & & & $\begin{array}{l}\text { unde } \\
\text { fined }\end{array}$ & 1 \\
\hline $\begin{array}{l}\text { colonic } \\
\text { Yes } \\
\text { No }\end{array}$ & $\begin{array}{l}103 \\
2\end{array}$ & $\begin{array}{l}14 \\
0\end{array}$ & & \\
\hline \multicolumn{4}{|l|}{ Preoperative } & \\
\hline $\begin{array}{l}\text { hes } \\
\text { No }\end{array}$ & $\begin{array}{l}96 \\
9\end{array}$ & $\begin{array}{l}14 \\
0\end{array}$ & fined & .60 \\
\hline Peritonitis & 80 & 12 & & \\
\hline $\begin{array}{l}\text { diffuse } \\
\text { localized }\end{array}$ & 25 & 2 & 1.76 & .73 \\
\hline \multicolumn{4}{|l|}{ Character of } & \\
\hline clear & 69 & 3 & 1.14 & 1 \\
\hline cloudy & 10 & 10 & 1.22 & 1 \\
\hline faecal & & 1 & 0.71 & 1 \\
\hline
\end{tabular}

A single perforation was found in 13 patients, two in 1 patient, and three in 1 patient. Simple suturing was the most frequently used treatment modality applied in spontaneous perforation as well as traumatic rupture of the small bowel. In cases of necrosis or dubious viability of the intestinal wall, the affected segment was resected.
Table 3. Procedures performed

\begin{tabular}{|c|c|}
\hline Procedure & $n$ \\
\hline Appendectomy & 30 \\
\hline Closing perforated peptic ulcer & 27 \\
\hline \multicolumn{2}{|l|}{ Suturing: } \\
\hline stomach & 2 \\
\hline small bowel & 25 \\
\hline colon & 1 \\
\hline uterus & 2 \\
\hline Resectioning bowel with direct anastomosis & 6 \\
\hline End enterostomy & 1 \\
\hline Hartmann's procedure & 2 \\
\hline Cholecystectomy & 2 \\
\hline Splenectomy & 2 \\
\hline Oophorectomy, tubectomy & 8 \\
\hline Hemicolectomy & 2 \\
\hline Adhesiolysis & 4 \\
\hline Explorative laparotomy & 10 \\
\hline Relaparotomy & 8 \\
\hline Take-down procedure & 3 \\
\hline Total & $135^{*}$ \\
\hline
\end{tabular}

Table 3 shows the procedures carried out. Three patients who underwent enterostomy as a first stage of the treatment were subsequently operated on 2-6 months thereafter to restore continuity of the gastro-intestinal tract with ileocecal $(n=1)$ and colorectal anastomoses $(n=2)$.

Postoperative period became complicated in 42 patients (32.3\%). The most common complications were surgical wound infection $(n=22,16.9 \%)$ and progressive peritonitis $(n=6,4.7 \%)$. Among others, less frequent complications of respiratory infection $(n=2)$, enterocutaneous fistula $(n=1)$, early postoperative intestinal obstruction $(n=1)$, and HIVinduced encephalopathy $(n=1)$ were recorded. Fourteen patients $(11.8 \%)$ died. 


\section{Discussion}

This retrospective observational study characterized 119 episodes of community-acquired peritonitis in a rural area in Zambia. Data obtained describe the main etiological factors for development of peritonitis and risk factors for postoperative death.

Peritonitis is a commonly seen surgical emergency on the African continent as well as in other countries $(1,2,4)$. In this study, the principal etiological factors leading to the development of peritonitis were perforation of peptic ulcer $(22.7 \%)$, acute appendicitis $(21.9 \%)$, PID (18.5\%) and spontaneous perforation of the small bowel $(13.5 \%)$. These data reflect the results of literature review provided by Sanjay Gupta et al. (2006), with exception of PID (3). PID is a common condition in developing countries. For example, in Zambia $10 \%$ of outpatient attendance at health institutions is due to sexually transmitted infections (10). In case of ineffective treatment in local clinic, pelvic inflammation could rapidly lead to development of intra-abdominal sepsis with corresponding morbidity and mortality. By including this cohort in the study, the author aimed to demonstrate the real epidemiology of peritonitis among the rural population, which comprises the majority of people living in this country. Most patients presented late to the hospital, exhibiting signs of well-established peritonitis. Delayed presentation of acute surgical conditions is wellknown among surgeons working in developing countries, and Zambia is not an exception (11). Delays in treatment of peritonitis are associated with increased morbidity and mortality in most of the research papers $(12,13)$. The length of the history of symptoms was different in cohorts of the patients, with the shortest delay being in abdominal trauma and the longest in perforated peptic ulcer. Factors associated with seeking care late investigated by Munyaneza et al. (2020) in a recent research performed in Rwanda (14) include sociodemographic characteristics, cost of care and travel time. Another well-recognized factor of delayed presentation is late referral from the local clinic and district hospitals. In this study, only nine patients (7.6\%) were admitted during the first 24 hours of the illness, and all survived. All deceased patients were admitted with duration of symptoms above 24 hours. This fact demonstrates the importance of timely admission and high predictive value of the medical history length for mortality.

Different scoring systems to assess severity and prognosis of peritonitis are found in literature $(15,16)$. Developed in 1987, Mannheim peritonitis index (MPI) remains highly recommended (17). Because of its simplicity and high predictive value, it was used in the current study. The MPI ranged from 10 to 32 points, with a mean of $22.1 \pm 5.2$. Patients were divided into three groups: those with an MPI of <21, those with MPI ranging from 21 to 27 , and those with MPI >27. MPI calculated for the patients who were successfully treated appeared to be significantly lower than the index defined for the patients who died $(21.2 \pm 4.5,95 \%$ CI $20.3-22.1$ and $29.9 \pm 2.4, \quad 95 \%$ CI 28.6-31.2 respectively, $p$ $<.00001)$. All 62 patients with MPI below 21 survived, while those above 27 appeared to have a serious risk of mortality (9 patients died and 6 survived). In the 21-27 cohort, index chances of favorable outcome are quite high (37 patients were cured and 5 died). All deceased patients had MPI of 27 and above and thus this value could be considered as an important cut-off in assessing individual prognosis for patients.

Organ dysfunction appears to be an important prognostic factor in peritonitis $(12,13)$. In this study, signs of organ failure were positive in 29 patients (24.4\%), and these patients bore statistically significant increased risk of death than the patients without organ dysfunction. By contrast, other components of MPI such as age over 50 years, malignancy and the degree of spreading of the inflammatory process in the peritoneal cavity were not statistically significant for the lethal outcome, although they demonstrated increased relative risk. These findings contradict data published by Sanjeev et al. (2016), who have shown statistically significant relation of mortality with female gender, duration of the symptoms above 24 hours, and presence of feculent exudate (13). Here we should consider the following. First, statistical power of the current study seems to be reduced by the small size of the groups and presence of disproportionate pairs inside the groups. Second, among 16 patients aged 50 or more years, only 3 had co-existing medical conditions, namely arterial hypertension which was under medication control (American Society of Anesthesiologists grade II). Thus, absence of systemic medical co-morbidities plays a protective role, diminishing a value of increased age per se. Next, all nine patients who were admitted within the first 24 hours of disease survived. Therefore, short history has clinical significance in reducing risk of death here. One should also recognize that with increasing duration of peritonitis, the risk of organ dysfunction increases, which was shown by one prospective study on enteric perforation peritonitis from India (2011) (15). The signs of impending or developed organ failure could be of especially high significance in low-resource rural environment in defining the level of care. Those patients with suspicion of organ dysfunction should have a very low threshold of referring to the tertiary hospital for 
intensive care and operative treatment. On the other hand, patients with negative criteria for organ failure and MPI of no more than 27 could be safely stayed in the lowvolume hospital for definitive surgical management. This practice could prevent life-threatening complications developing during the transfer, would relieve tertiary hospitals of their heavy surgical load, and will definitely contribute to maintenance of surgical expertise in surgeons working at rural hospitals. In this respect, the current study advocates recommendations outlined by the Lancet Commission for global surgery for 2030 in targets for access to timely, essential surgery and surgical volume (9).

Surgery to control intra-abdominal sepsis was performed early after intensive IV resuscitation. The length of preoperative management ranged from 2 to 24 hours and was not statistically different between the patient cohorts. It depended on the clinical condition of the patient, uncertainty in diagnosis, and immediate availability of medical staff. If system-based delays threatened the patient's condition, they were urgently referred to the tertiary hospital. This group was not large and was excluded from the study. Individual approach to the patients with special attention to preoperative optimization allowed most patients $(94.9 \%)$ to undergo surgery without intraoperative and immediate postoperative complications.

Pelvic inflammatory disease - a spectrum of diseases ranging from cervicitis to pyosalpinx and tubo-ovarian abscess - is a common infection in women of reproductive age in industrialized nations and developing countries (18). Although most patients with PID could be successfully managed with antibacterial treatment, there are situations when inflammatory process spreads to the whole peritoneal cavity (19). In these cases, surgery became necessary aiming at the source control of abdominal sepsis; surgery was performed on 22 patients in this study. In surgical treatment of small bowel perforations of spontaneous and traumatic etiology, the author considers primary suturing and direct anastomosis to be safe even in the presence of diffuse peritonitis, as there was no incidence of leakage. We could not histologically and hematologically confirm all the causes of spontaneous ileal perforation not related to intestinal obstruction, but clinically they looked like typhoid perforation.

Wound infection is the most common postoperative complication in patients with peritonitis (20), and it ranges from superficial collection of pus to severe necrotizing infection. Rates for wound sepsis vary significantly from country to country, from 8 to $71.4 \%$ (4, 21). In this study, postoperative wound sepsis developed in $16.9 \%$ of patients (22/130). In 19 patients, a collection of pus beneath the suture line was found. Two patients experienced deep wound sepsis and in one case a necrotizing infection of the abdominal wall (Meleney's gangrene) developed. These patients required appropriate antibiotic cover and serial debridement under general anesthesia. All three patients were successfully discharged, the last on postoperative day 43 .

In seven cases of ongoing postoperative peritonitis, five developed due to inflammatory exudate recollecting and intra-abdominal abscesses forming during the hospital stay $(n=6)$ or after discharge $(n=1)$. In two patients with perforated peptic ulcer, postoperative period was complicated by leakage at the suture line. These patients were re-explored, one of them twice. The author used ondemand relaparotomy strategy that is in line with current clinical practice and international literature (22), and recommended as a viable option by the World Society of Emergency Surgery (2017) (1). One more relaparotomy was done for early postoperative intestinal obstruction. Two out of seven re-operated patients died.

Reported mortality from peritonitis worldwide differs significantly, varying from $6.4 \%$ to $25 \%(3,23)$. The rate of mortality in this work was $11.8 \%$. Differential analysis showed that the highest contributor to death toll was perforation of peptic ulcer ( 7 out of total 14 deaths). The mortality rate from this source of peritonitis in the study was 26\% (7/27), which lies within ranges found in literature, from $5.8 \%$ in Turkey (2015) (24) to $37 \%$ at a tertiary hospital in Zambia (2011) (11).

\section{Limitations}

This is an observational retrospective study with a rather small size of patient cohorts performed in a low-volume hospital. It was assumed that patients entered in the study received reasonably standard care according to recent evidence-based recommendations. However, systemrelated problems associated with lack of resources and facilities may have led to inadequate management, thus contributing negatively to outcomes. On the other hand, some patients preoperatively and seven operated patients were excluded from the study as they were transferred to the tertiary institution in complicated state with development of multi-organ failure, for further management. Loss of these patients for statistical analysis could overestimate treatment effect and reduce the validity of the study. 


\section{Conclusion}

The main sources of peritonitis among the rural population of Zambia, according to the current study, were perforated peptic ulcer, acute appendicitis and PID, next was small bowel perforation. Perforated peptic ulcer appeared to be the most significant contributor to inhospital mortality in patients with peritonitis.

The study emphasizes the significance of organ failure for fatal outcome in peritonitis. Patients with short history and without signs of organ failure could be successfully treated in low-volume rural surgical hospitals that have an uninterrupted access to the operating theatre. MPI is a highly useful and informative tool for predicting patient outcome.

Larger-scale and prospective studies are needed to further validate the findings in this study, and to develop recommendations for surgeons working in rural areas.

\section{References}

1. Sartelli M, Chichom-Mefire A, Labricciosa FM, et al. The management of intra-abdominal infections from a global perspective: 2017 WSES guidelines for management of intraabdominal infections. World J Emerg Surg. 2017;12:29.

2. Chichom-Mefire A, FonTabe A, Ngowe-Ngowe M. Which cause of diffuse peritonitis is the deadliest in the tropics? A retrospective analysis of 305 cases from the south-west region of Cameroon. World J Emerg Surg. 2016;11:14.

3. Gupta S, Kaushik R. Peritonitis - the Eastern experience. World J Emerg Surg. 2006;1:13

4. Mutabazi E, Bonane A, Ndibanje AJ, et al. Epidemiological study of peritonitis among children and factors predicting mortality at a tertiary referral hospital in Rwanda. East Cent Afr J Surg. 2017;22(3):21-28.

5. Ugochukwu AI, Amu OC, Nzegwu MA. Ileal perforation due to typhoid fever-Review of operative management and outcome in an urban centre in Nigeria. Int J Surg. 2013;11(3):218-22.

6. Ojuka KD. Typhoid ileal perforation: A review of a rural district hospital experience. Ann Afr Surg. 2012;9(2):93-96.

7. McConkey SJ. Case series of acute abdominal surgery in rural Sierra Leone. World J Surg. 2002;26(4):509-513.

8. Willmore WS, Hill AG. Acute appendicitis in a Kenyan rural hospital. East Afr Med J. 2001;78(7):355-357.

9. Meara JG, Leather AM, Hagander L, et al. Global Surgery 2030: Evidence and solutions for achieving health, welfare, and economic development. Lancet. 2015;386:569-624.

10. Kasanda G. Prevalence and determinants of Neisseria gonorrhea and Chlamydia trachomatis infections in patients with pelvic inflammatory disease in Lusaka, Zambia. Med J Zambia. 2012;39(4):24-32.
11. Sondashi KJ, Odimba BFK, Kelly P. A cross-sectional study on factors associated with perforated peptic ulcer disease in adults presenting to UTH, Lusaka. Med J Zambia. 2011;38(2):15-22.

12. Ntirenganya F, Ntakiyiruta G, Kakande I. Prediction of outcome using the Mannheim peritonitis index in patients with peritonitis at Kigali University Teaching Hospital. East Cent Afr J Surg. 2012;17(2):52-64.

13. Sanjeev S, Sumitoj S, Nikhil M, et al. Assessment of severity of peritonitis using Mannheim peritonitis index. Nigerian $\mathbf{J}$ Surg. 2016;22(2):118-122.

14. Munyaneza M, Jayaraman S, Ntirenganya F, et al. Factors Influencing Seeking and Reaching Care in Patients with Peritonitis in Rwanda. J Surg Res. 2020; 246: 236-242.

15. Kumar S, Gupta A, Chaudhary S, et al. Validation of the use of POSSUM score in enteric perforation peritonitis - results of a prospective study. Pan Afr Med J. 2011; 9:22.

16. Sartelli M, Abu-Zidan FM, Labricciosa FM, et al. Physiological parameters for Prognosis in Abdominal Sepsis (PIPAS) Study: A WSES observational study. World J Emerg Surg. 2019;14:34

17. Wacha H, Linder MM, Feldman U, et al. The Mannheim Peritonitis Index. An instrument for the intraoperative prognosis of peritonitis. Theor Surg. 1987;1:169-177.

18. Brunham RC, Gottlieb SL, Paavonen J. Pelvic Inflammatory Disease. N Engl J Med. 2015; 372:2039-2048.

19. Schindlbeck C, Dziura D, Mylonas I. Diagnosis of pelvic inflammatory disease: Intra-operative findings and comparison of vaginal and intra-abdominal cultures. Arch Gynecol Obstet. 2014;289(6):1263-9.

20. Ademola TO, Oludayo SA, Olowookere AS, et al. Clinicopathological review of 156 appendicectomies for acute appendicitis in children in Ile-Ife, Nigeria: A retrospective analysis. BMC Emerg Med. 2015;15:7.

21. Ojuka A, Ekwaro L, Kakande I. Causes and patterns of peritonitis at St. Fransis Hospital Nsambya, Kampala, Uganda. East Cent Afr J Surg. 2014;19(3):99-106.

22. Scriba MF, Laing GL, Bruce JL, et al. The role of planned and on-demand relaparotomy in the developing world. World $\mathbf{J}$ Surg. 2016;40(7):1558-64.

23. Theunissen C, Cherifi S, Karmali R. Management and outcome of high-risk peritonitis: A retrospective survey 2005 2009. Int J Inf Dis. 2011;15:e769-e773.

24. Unver M, Frrat Ö, Ünalp ÖV, et al. Prognostic factors in peptic ulcer perforations: A retrospective 14-year study. Int Surg. 2015;100:942-948. 